\title{
A pilot trial on subjects with lactose and/or oligosaccharides intolerance treated with a fixed mixture of pure and enteric-coated $\alpha$ - and $\beta$-galactosidase
}

\author{
This article was published in the following Dove Press journal: \\ Clinical and Experimental Gastroenterology \\ 19 February 2015 \\ Number of times this article has been viewed
}

\author{
Francesco Di Pierro' \\ Alexander Bertuccioli \\ Eleonora Marini ${ }^{3}$ \\ Leandro Ivaldi ${ }^{4}$ \\ 'Velleja Research, Milan, Italy; ${ }^{2}$ Italian \\ Association Fitness and Medicine, \\ Fano, PU, Italy; ${ }^{3}$ Pharmextracta, \\ Pontenure, Piacenza, Italy; ${ }^{4}$ Digestive \\ Endoscopic Department, Ceva \\ Hospital, Ceva, Cuneo, Italy
}

\begin{abstract}
Aim: Lactose and complex carbohydrates maldigestion, common food intolerances due to low gut content of $\alpha$ - and $\beta$-galactosidase, lead to abdominal symptoms including pain, diarrhea, bloating, flatulence, and cramping. Commonly, intolerant patients are advised by physicians to avoid the offending foods (dairy foods, cereals, beans, etc). This food-limiting option, however, has possible nutritional risks. We have therefore evaluated the impact of using pure, entericcoated $\alpha$-plus $\beta$-galactosidase on gut symptoms in intolerant subjects instead of avoidance of the offending foods.
\end{abstract}

Methods: Sixteen subjects intolerant to lactose and/or complex carbohydrates were enrolled and evaluated in terms of gut symptoms with 1) uncontrolled diet, 2) diet devoid of offending foods, and 3) uncontrolled diet along with pure, enteric-coated $\alpha$ - and $\beta$-galactosidase (DDM Galactosidase $\left.^{\circledR}\right)$.

Results: Even with the uncontrolled diet, intolerant subjects treated with DDM Galactosidase ${ }^{\circledR}$ exhibited reduced gut symptoms (bloating, flatulence, diarrhea, and constipation) significantly better than the control treatment as well as having a diet devoid of offending foods.

Conclusion: DDM Galactosidase ${ }^{\circledR}$ is a valid and safe optional treatment to counteract lactose and complex carbohydrate intolerance in subjects who prefer not to avoid, at least partially, offending foods.

Keywords: lactase, lactose intolerance, complex carbohydrate intolerance

\section{Introduction}

Lactose maldigestion occurs when the content of lactase enzyme, also known as $\beta$-galactosidase, is reduced in the small bowel mucosa. This reduction, which typically begins early in childhood, affects more than $70 \%$ of the world's population with abdominal and gut symptoms including pain, diarrhea, bloating, flatulence, and cramping. ${ }^{1}$ These symptoms are the consequence of undigested lactose that, after reaching the colon, is fermented to produce acetate, carbon dioxide, hydrogen gas, sulfur compounds, and methane. These fermentation products along with the osmotic effects of lactose, cause most of the symptoms frequently associated with lactose intolerance. ${ }^{2}$ Commonly, lactoseintolerant patients are advised by physicians to avoid dairy foods. However, nutritionists often contest such advice, since they lead to significant nutritional risks such as reduced plasma and tissue content of calcium, potassium, vitamin D, B vitamins, and high-quality proteins. ${ }^{3}$ Low intake of minerals, vitamins, and dairy proteins can possibly lead to bone fracture, osteoporosis, and other adverse health outcomes. ${ }^{4,5}$ Beyond lactose intolerance, although to a lesser degree in terms of incidence, complex carbohydrate intolerance (CCI)
Correspondence: Francesco Di Pierro Velleja Research, Viale Lunigiana 23, Milano, Italy

Tel +393495 527663

Fax +390523 5II894

Email f.dipierro@vellejaresearch.com 
affects a significant percentage of individuals who exhibit gut symptoms after eating starches, beans, or similar foods. ${ }^{6}$ As lactose is the problem for lactose intolerants, oligosaccharides like raffinose, stachyose, and verbascose are likely involved in CCI. ${ }^{7,8}$ Again, as lactose intolerance symptomatology is due to gut $\beta$-galactosidase deficit, symptoms of CCI are due to $\alpha$-galactosidase deficit. ${ }^{9}$ Administration of $\beta$-galactosidase to lactose-intolerant subjects and $\alpha$-galactosidase in the case of CCI have been shown clinically to counteract gut symptoms both in adults and in children. ${ }^{10-13} \alpha$ - and $\beta$-galactosidases are both enzymatic proteins and as such, to work, they need to be protected from gastric juice when orally administered. ${ }^{14,15}$ Therefore, we decided to test the clinical effect of the entericcoated formula containing both the enzymes in a group of subjects with either a diagnosis of lactose and/or oligosaccharides intolerance, verifying the impact of the treatment in comparison with an unrelated vitamin B-based treatment and with a diet devoid of dairy food or oligosaccharides in the case of CCI.

\section{Materials and methods Study design}

This 7-week, single-blinded, observational, controlled trial was conducted in accordance with the principles stated in the Declaration of Helsinki and consistent with Good Clinical Practice, as defined by the International Conference on Harmonization and in accordance with the ethical principles underlying European Union Directive 2001/20/EC and the United States Code of Federal Regulations, Title 21, Part 50 (21CFR50). ${ }^{16}$ Protocol, subject consent, and privacy forms were approved by the local review board. All patients provided their written informed consent to participate in this study after a full explanation of the study had been given. The study was performed in a single center in Italy between March and June 2014 on 16 patients enrolled on the basis of their diagnoses, confirmed by gastroenterologist, of lactose intolerance and/or CCI. Sixteen patients completed the study and were evaluated from a statistical point of view.

\section{Lactose intolerance diagnosis}

In order to confirm lactose intolerance, subjects underwent a $25 \mathrm{~g}$ lactose challenge in the clinic. Lactose intolerance gut symptoms and hydrogen production via hydrogen breath test (HBT) were assessed for 6 hours post-lactose challenge. A positive HBT was defined as a hydrogen gas elevation of 20 parts per million (ppm) at two time-points within the 6 hours following a lactose-loading dose. Out of 16 , 12 patients were diagnosed as being lactose intolerant.

\section{Complex carbohydrate intolerance}

In order to confirm $\mathrm{CCI}$, or the chance of having a subject having double intolerance (lactose intolerance plus CCI), we proceeded with the diagnosis by exclusion; ${ }^{17}$ that is, avoiding lactose-based meals and excluding the assumed offending foods (beans, soy, and cereals), then reintroducing them. The absence and the presence of gut symptoms according to the absence or presence of the offending foods determined the diagnosis of CCI. Out of 16, seven individuals were found to be oligosaccharide intolerant. Among them, three were also lactose intolerant.

\section{Inclusion criteria}

The inclusion criteria were: aged between 18 and 75 years; signed the informed consent form; and diagnosis of lactose intolerance and/or CCI.

\section{Exclusion criteria}

The exclusion criteria were: age below 18 or over 75 years; failure to sign the informed consent form; diagnosis of diabetes mellitus, irritable bowel syndrome, inflammatory bowel disease, and celiac disease, or a history of surgery known to alter the normal function of the gastrointestinal tract; diagnosis of major depression; suicidal tendencies; neurological diseases; epilepsy; pregnancy; breastfeeding; diagnosis of liver cirrhosis; severe heart failure; or hepatic and/or renal impairment.

\section{Study protocol}

The study scheme is presented in Figure 1. After enrolling, all subjects spent the first week with an uncontrolled diet; during the second week, lactose-based food were excluded from their diet; during the third week, all lactose-based foods were reintroduced (one portion every 2 days); during the fourth week, beans, soy, and cereals were excluded (and lactose-based foods were kept as one portion every 2 days); during the fifth week, all offending foods were reintroduced (one portion per day of lactose-based food and alternatively, one portion per day of oligosaccharidebased food); the sixth week was identical to the fifth one, during which the control therapy was tested; finally, during the seventh week, again identical to the fifth one, the tested therapy was administered. As agreed with the enrolled subjects, "one portion" indicated 25-50 g of offending foods. During each week of the trial, all participants had to answer a written questionnaire reporting a score ( $0-5$ according to perceived severity) for any typical or atypical symptoms of food intolerance: abdominal pain, borborygmi, bloating, 


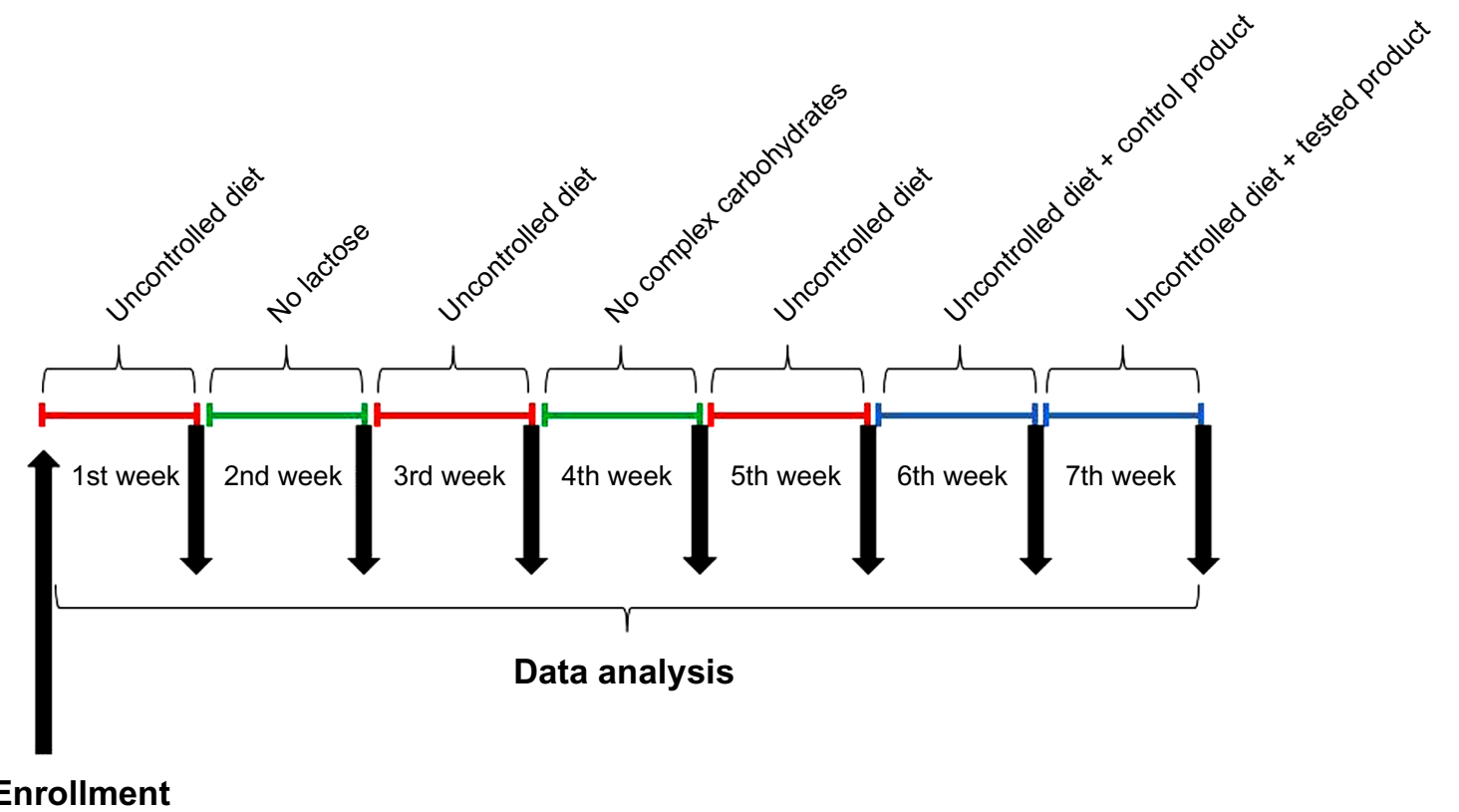

Figure I Scheme protocol.

flatulence, diarrhea, nausea, vomit, constipation, articular pain, muscle pain, sleepiness, vertigo, oral stomatitis, acne, itch, rhinitis, and sore throat. After every week, weight, body mass index, and waist circumference were measured in order to evaluate relevant weight loss.

\section{Tested products}

In our study, as control treatment, we used a food supplement formula (DDM Betaine ${ }^{\circledR}$, Omeopiacenza, Milan, Italy) containing betaine ( $250 \mathrm{mg} /$ tablet $)$, vitamin B6 (3 $\mathrm{mg} /$ tablet $)$, vitamin B12 (3.75 $\mu \mathrm{g} /$ tablet $)$, and folate $(0.4$ $\mathrm{mg} /$ tablet) and, as tested product, an enteric-coated food supplement formula (DDM Galactosidase ${ }^{\circledR}$, Omeopiacenza) containing pure $\alpha$-galactosidase at $200 \mathrm{Gal} / \mathrm{U}$ corresponding to $20 \mathrm{mg} /$ tablet and pure $\beta$-galactosidase at $200 \mathrm{Lac} / \mathrm{U}$ corresponding to $2 \mathrm{mg} /$ tablet. DDM Betaine ${ }^{\circledR}$ (notified to Italian Ministry of Health on March 13, 2009; notification number: 42528) and DDM Galactosidase ${ }^{\circledR}$ (notified to Italian Ministry of Health on March 13, 2009; notification number: 42537) are undistinguishable products from a size, weight, odor, and color standpoint and the study participants were not aware if they were under treatment with the assumed control or with the assumed active product. Both finished products are manufactured at Procemsa Farmaceutici, Nichelino, Italy.

\section{Product administration}

Both products were administered by oral route 15 minutes before breakfast, lunch, and dinner at the dosage of one tablet per time. The daily dosages for both products were thus three tablets per day.

\section{Endpoints}

The primary efficacy endpoints of the study were assessed by symptom score analysis. Secondary endpoints included the occurrence of side effects different from those assumed to drop into the symptoms evaluated as primary endpoints and compliance. Compliance was scored as very poor, poor, fair, good, and excellent. Primary and secondary endpoints were evaluated throughout the study at the end of each week. Nevertheless, subjects could contact the gastroenterologist responsible for the study at any time.

\section{Statistical analysis}

To analyze differences versus baseline score within the same treatment group and differences between the groups, the Wilcoxon signed-rank test was used. To analyze differences in terms of anthropometric measurements, the exact Wilcoxon test was used. Values were considered statistically significant at $P<0.05$.

\section{Results}

According to the inclusion and exclusion criteria, 16 subjects (six males and ten females) were enrolled into the study. All subjects completed the study. The characteristics of the participants are shown in Table 1. At the end of the study, no significant modifications in terms of weight, waist circumference, and body mass index were observed in comparison 
Table I Characteristics of participants on enrolment

\begin{tabular}{ll}
\hline & Enrolled subjects \\
\hline Sex (males/females) & $6 / 10$ \\
Lactose intolerant & $12 / 16$ \\
$\mathrm{CCl}$ & $7 / 16$ \\
Lactose intolerant and CCl & $3 / 16$ \\
Age (years) & $38.2 \pm 13.9$ \\
Weight $(\mathrm{kg})$ & $70.4 \pm 13.6$ \\
Height $(\mathrm{cm})$ & $166.3 \pm 9.7$ \\
Waist circumference $(\mathrm{cm})$ & $86.6 \pm 9.4$ \\
Body mass index & $25.4 \pm 3.9$ \\
\hline
\end{tabular}

Note: All values are expressed as median \pm standard deviation.

Abbreviation: $\mathrm{CCl}$, complex carbohydrate intolerance.

with the same parameters shown in Table 1 (data not shown). According to the results shown in Figure 2, where global scores trends are reported, during the first week of the trial, during which subjects were not controlled in terms of diet, typical symptoms of lactose and/or oligosaccharides intolerance were observed with a total score of 174. During the second week, the diet was lactose-free and symptoms were reduced, with a global score of 103 showing that the simple absence of lactose in the diet improved the subjects' well-being significantly. During the third week of the trial, lactose was reintroduced and the symptom score rose up to 145. During the fourth week of the trial, lactose was reintroduced but food provoking oligosaccharide intolerance was removed from the diet. This approach caused a reduction of the global score to 114 . On reintroducing oligosaccharide-based foods (beans, soy, cereals), the global score rose up to 137. Administering a B vitamins plus Betaine-based product to subjects did not change the global score $(=155)$ in the case of uncontrolled diet. Conversely, the administration of enteric-coated enzymes able to digest lactose and oligosaccharides reduced global symptoms in a highly significant way (total score $=63$ ) demonstrating that, even in the case of uncontrolled diet, the use of the two purified enzymes substantially improved the subjects' well-being. In Figure 3 the single score trends, as $\mathrm{M} \pm \mathrm{SD}$, are shown. From a statistical standpoint (Table 2), the control product (B vitamins plus Betaine) did not significantly improve any parameters. On the contrary, the tested product (purified, enteric-coated $\alpha / \beta$-galactosidase) resulted to be highly significant versus $\mathrm{T}=0$ (enrolment) and versus control treatment especially as regards to the typical symptoms (bloating, flatulence, diarrhea, and constipation) of lactose and oligosaccharide intolerance. Neither in Figures 2 and 3 nor in Table 2 some parameters established by protocol (vomit, vertigo, oral stomatitis, rhinitis, and sore throat) have been reported due to their values corresponding to zero for the whole length of the study. From a safety standpoint, both the control and tested product were well-tolerated and no sign or symptom other than the ones included in the questionnaire appeared. Compliance was overlapping in the two groups of treatment, being "good" for all the 16 subjects completing the study (data not shown).

\begin{tabular}{|c|c|c|c|c|c|c|c|}
\hline & $\begin{array}{l}\text { Uncontrolled } \\
\text { diet }\end{array}$ & No lactose & $\begin{array}{l}\text { Uncontrolled } \\
\text { diet }\end{array}$ & No $\mathrm{CC}^{* *}$ & $\begin{array}{l}\text { Uncontrolled } \\
\text { diet }\end{array}$ & $\begin{array}{c}\text { Control } \\
\text { product* }\end{array}$ & $\begin{array}{c}\text { Tested } \\
\text { product }^{*} \\
\end{array}$ \\
\hline & 1st week & 2nd week & 3rd week & 4th week & 5th week & 6th week & 7th week \\
\hline Abdominal pain & 11 & 2 & 9 & 4 & 6 & 4 & 1 \\
\hline Borborygmi & 21 & 8 & 15 & 10 & 11 & 11 & 5 \\
\hline Bloating & 33 & 24 & 31 & 17 & 32 & 33 & 14 \\
\hline Flatulence & 34 & 24 & 31 & 22 & 34 & 37 & 14 \\
\hline Diarrhea & 16 & 0 & 10 & 5 & 5 & 23 & 4 \\
\hline Nausea & 4 & 1 & 3 & 0 & 3 & 4 & 1 \\
\hline Constipation & 15 & 15 & 14 & 25 & 19 & 7 & 6 \\
\hline Articular pain & 10 & 7 & 9 & 9 & 7 & 8 & 6 \\
\hline Muscle pain & 3 & 4 & 4 & 4 & 2 & 4 & 3 \\
\hline Sleepiness & 13 & 13 & 11 & 6 & 8 & 14 & 4 \\
\hline Acne & 3 & 0 & 0 & 3 & 0 & 0 & 0 \\
\hline Itch & 11 & 5 & 8 & 9 & 10 & 10 & 5 \\
\hline Total score & 174 & 103 & 145 & 114 & 137 & 155 & 63 \\
\hline
\end{tabular}

Figure 2 Score trends (per single parameter and global) during the 7 weeks of trial. Notes: *Plus uncontrolled diet; **CC.

Abbreviation: CC, complex carbohydrates. 


$\begin{array}{llllllll} & \begin{array}{l}\text { Uncontrolled } \\ \text { diet }\end{array} & & & \end{array}$

Figure 3 Score trends (median \pm standard deviation) during the 7 weeks of trial. Notes: *Plus uncontrolled diet; **CC.

Abbreviation: CC, complex carbohydrates.

\section{Discussion}

Current strategies for the treatment of lactose intolerance and CCI are: 1) avoidance of lactose-containing dairy foods (yogurt, milk, cheese, and ice cream) and/or avoidance of oligosaccharides (such as raffinose, stachyose, and verbascose)-based foods (cereals, beans, soy, etc) or 2 ) the use of drugs or supplements containing digestive enzymes able to digest lactose and/or oligosaccharides. The latter are mainly exclusively formulated to contain lactase ( $\beta$-galactosidase), while just a few contain purified $\alpha$-galactosidase as a single active ingredient (to the authors' knowledge, the only such product is Beano ${ }^{\circledR}$ [Prestige Brands, Tarrytown, NY, USA]).

Table 2 Symptom variation (\%) due to treatments

\begin{tabular}{llll}
\hline & $\begin{array}{l}\text { Control vs } \\
\text { T=0 }\end{array}$ & $\begin{array}{l}\text { Treatment vs } \\
\mathbf{T}=\mathbf{0}\end{array}$ & $\begin{array}{l}\text { Treatment vs } \\
\text { Control }\end{array}$ \\
\hline Abdominal pain & -63.6 & $-90.9 *$ & $-75.0^{*}$ \\
Borborygmi & -47.6 & $-76.2^{* *}$ & -54.5 \\
Bloating & 0.0 & $-57.6 * *$ & $-57.6 * *$ \\
Flatulence & 8.82 & $-58.8^{* *}$ & $-62.2^{* *}$ \\
Diarrhea & 0.0 & $-75.0^{* *}$ & $-75.0 * *$ \\
Nausea & 0.0 & -75.0 & -75.0 \\
Constipation & 0.0 & $-66.6 * *$ & $-66.6 * *$ \\
Articular pain & -20.0 & -40.0 & -25.0 \\
Muscle pain & -33.3 & 0.0 & -25.0 \\
Sleepiness & -7.7 & $-69.2 *$ & $-71.4^{*}$ \\
Acne & -100 & -100 & 0.0 \\
Itch & -9.1 & -54.6 & -50.0 \\
\hline
\end{tabular}

Notes: $* P<0.05 ; * * P<0.01$.
Our study demonstrates that the use of the tested product, enteric-coated, containing both the enzymes able to generate effective digestion of lactose and of raffinose, stachyose, and verbascose, was effective in reducing, in a significant manner, abdominal symptomatology characterizing these food intolerances. This result highlights how it is possible, for intolerant subjects, to manage a normal diet approach without the need of avoiding offending foods. This approach is advantageous, since it reduces the unfavorable consequences caused by food limitation. The use of the two enteric-coated enzymes reduce in a significant manner both versus $\mathrm{T}=0$ and versus control treatment, symptoms highly characterizing food intolerances like bloating, flatulence, diarrhea, and constipation. Treatment with the two enzymes also significantly reduced abdominal pain and sleepiness. Other symptoms, including itch or borborygmi, were also reduced by the treatment but reduction did not reach a significant result likely due to the small number of the enrolled subjects. Indeed, this is likely a limit of the study. Other possible bias include not being a double-blinded study and not having a real placebo group. Besides, the scheme of the study, during which subjects alternately underwent, week after week, an uncontrolled diet followed by a diet devoid of the two kinds of offending foods, then again to an uncontrolled diet with the addition of a therapy aimed to counteract intolerances, is a good compromise in relation to these possible bias. In fact, all the 16 subjects were evaluated from a symptomatic point of view three times (48 evaluations) in the absence of 
controlled diet; then, the same subjects were evaluated from a symptomatic point of view twice (32 evaluations) when undergoing a diet devoid of offending foods; finally, they were evaluated from a symptomatic point of view twice (32 evaluations) in relation to a therapy associated with uncontrolled diet. The evidence of the results is that in these intolerant subjects, the uncontrolled diet resulted in a mean total score of $152(174+145+137)$; by avoiding offending foods, a mean total score of $108.5(103+114)$ was found; finally, uncontrolled diet plus enzymes gave rise to a mean total score of 63. By considering that a total score of 155 , overlapping with the result from the uncontrolled diet, was observed with uncontrolled diet plus control treatment, the treatment with the two purified and enteric-coated enzymes seems to be suitable and useful. Intolerant subjects owe their complaints to a lack of the proper enzymes needed to digest lactose and oligosaccharides in the bowel. The use of a product constituted by a mixture of pure enzymes reportedly able to digest lactose and oligosaccharides, respectively, corresponds to a real enzymatic replacement therapy able to effectively counteract these intolerances. A new study is now ongoing to evaluate the effects of these two enteric-coated enzymes on a larger number of subjects. So far, on the basis of our preliminary results, we conclude that the administration of DDM Galactosidase could be a possible, rationale, safe, and effective means to counteract lactose and oligosaccharides intolerance and a possible therapeutic option to be chosen instead of avoiding the consumption of offending foods (milk derivatives, beans, cereals, etc).

\section{Acknowledgment}

The authors wish to thank Dr Paolo Risso for the statistical analysis of the results.

\section{Disclosure}

FDP is the main formulator of DDM Galactosidase ${ }^{\circledR}$. AB and EM are PharmExtracta ${ }^{\circledR}$ consultants, a sister company of Omeopiacenza $^{\circledR}$, the Italian firm trading the tested product. LI reports no conflicts of interest in this work.

\section{References}

1. Scrimshaw NS, Murray EB. The acceptability of milk and milk products in populations with a high prevalence of lactose intolerance. Am J Clin Nutr. 1988;48(4 Suppl):1079-1159.

2. Bond JH, Currier BE, Buchwald H, Levitt MD. Colonic conservation of malabsorbed carbohydrate. Gastroenterology. 1980;78(3):444-447.

3. Perino A, Cabras S, Obinu D, Cavalli Sforza L. Lactose intolerance: a non-allergic disorder often managed by allergologists. Eur Ann Allergy Clin Immunol. 2009;41(1):3-16.

4. Di Stefano M, Veneto G, Malservici S, et al. Lactose malabsorption and intolerance and bone mass. Gastroenterology. 2002;122(7): 1793-1799.

5. Suchy FJ, Brannon PM, Carpenter TO, et al. NIH consensus development conference statement: lactose intolerance and health. NIH Consens State Sci Statements. 2010;27(2):1-27.

6. Levine B, Weisman S. Enzyme replacement as an effective treatment for the common symptoms of complex carbohydrate intolerance. Nutr Clin Care. 2004;7(2):75-81.

7. Ibrahim SA, Alazzeh AY, Awaisheh SS, Song D, Shahbazi A, AbuGhazaleh AA. Enhancement of alpha- and beta-galactosidase activity in Lactobacillus reuteri by different metal ions. Biol Trace Elem Res. 2010;136(1):106-116.

8. Fan PH, Zang MT, Xing J. Oligosaccharides composition in eight food legumes species as detected by high-resolution mass spectrometry. J Sci Food Agric. Epub September 30, 2014. doi: $10.1002 /$ jsfa. 6940

9. Di Stefano M, Miceli E, Gotti S, Missanelli A, Mazzocchi S, Corazza GR. The effect of oral alpha-galactosidase on intestinal gas production and gas-related symptoms. Dig Dis Sci. 2007;52(1):78-83.

10. Medow MS, Thek KD, Newman LJ, Berezin S, Glassman MS, Schwarz SM. Beta-galactosidase tablets in the treatment of lactose intolerance in pediatrics. Am J Dis Child. 1990;144(11):1261-1264.

11. Sanders SW, Tolman KG, Reitberg DP. Effect of a single dose of lactase on symptoms and expired hydrogen after lactose challenge in lactose-intolerant subjects. Clin Pharm. 1992;11(6):533-538.

12. Ganiats TG, Norcross WA, Halverson AL, Burford PA, Palinkas LA. Does Beano prevent gas? A double-blind crossover study of oral alphagalactosidase to treat dietary oligosaccharide intolerance. J Fam Pract. 1994;39(5):441-445.

13. Lettieri JT, Dain B. Effects of beano on the tolerability and pharmacodynamics of acarbose. Clin Ther. 1998;20(3):497-504.

14. Ramirez FC, Lee K, Graham DY. All lactase preparations are not the same: results of a prospective, randomized, placebo-controlled trial. Am J Gastroenterol. 1994;89(4):566-570.

15. Xenos K, Kyroudis S, Anagnostidis A, Papastathopoulos P. Treatment of lactose intolerance with exogenous beta-D-galactosidase in pellet form. Eur J Drug Metab Pharmacokinet. 1998;23(2):350-355.

16. World Medical Association. World Medical Association Declaration of Helsinki: ethical principles for medical research involving human subjects. J Postgrad Med. 2002;48(3):206-208.

17. Lloyd-Still JD, Listernick R, Buentello G. Complex carbohydrate intolerance: diagnostic pitfalls and approach to management. J Pediatr. 1988;112(5):709-713.
Clinical and Experimental Gastroenterology

\section{Publish your work in this journal}

Clinical and Experimental Gastroenterology is an international, peerreviewed, open access journal, publishing all aspects of gastroenterology in the clinic and laboratory, including: Pathology, pathophysiology of gastrointestinal disease; Investigation and treatment of gastointestinal disease; Pharmacology of drugs used in the alimentary tract;

\section{Dovepress}

Immunology/genetics/genomics related to gastrointestinal disease. This journal is indexed on CAS. The manuscript management system is completely online and includes a very quick and fair peer-review system. Visit http://www.dovepress.com/testimonials.php to read real quotes from published authors. 